\title{
Oral Ibuprofen Induced Spontaneous Intestinal Perforation in a Preterm Infant
}

\author{
Preterm Bir Bebekte Oral Ibuprofenin Indüklediği Spontan Intestinal Perforasyon
}

\author{
Şahin Hamilçıkan, Övgü Büke, Sultan Bent, Esra Özcan, Emrah Can \\ University of Health Sciences, Istanbul Bağcllar Training and Research Hospital, Department of Pediatrics, Istanbul, Turkey
}

\begin{abstract}
Ibuprofen is often used as an alternative for patent ductus arteriosus (PDA) management in preterm infants. The reported side effects are fewer than those of indomethacin. Spontaneous intestinal perforation differs from necrotizing enterocolitis, presents an early clinical picture and usually occurs after corticosteroid treatment in preterm infants. We present a case of a preterm neonate with spontaneous intestinal perforation induced by oral ibuprofen treatment for PDA.

Keywords: lbuprofen, preterm, spontaneous intestinal perforation
\end{abstract}

ÖZ

Ibuprofen prematüre bebeklerde patent duktus arteriozus (PDA) tedavisinde sıklıkla alternatif olarak kullanılmaktadır. Yan etkileri indometazinden daha az olarak bildirilmektedir. Spontan intestinal perforasyon sıklıkla steroid alımı sonrasında prematüre bebeklerde görülen nekrotizan enterokolitten farkı bir klinik tablodur. Bu olguda PDA tedavisi için oral ibuprofen tedavisi alan prematüre bir yenidoğanda tedavi ile ilişkili spontan intestinal perforasyon olgusu sunuldu.

Anahtar Kelimeler: Ibuprofen, prematüre, spontan intestinal perforasyon

\section{Introduction}

Spontaneous intestinal perforation (SIP) of the newborn is a single intestinal perforation, characteristically present at the terminal ileum and usually consists in low birth neonates or babies who receive corticosteroid treatment early in life (1-4). We present a case of a neonate without any significant necrotizing enterocolitis (NEC) signs, developing SIP related to oral ibuprofen usage for patent ductus arteriosus (PDA) closure treatment.

\section{Case Report}

Twin babies of a Syrian mother without antenatal follow-up were born via cesarean section at the $27^{\text {th }}$ week of gestation. One baby was 1250 grams at birth with an Apgar score of
5 in the first minute. He was intubated and transferred to neonatal intensive care unit (NICU) for respiratory distress. Total parenteral nutrition as well as minimal enteral feeding with breast milk was started on the admission day. On follow-up, oral intake was increased to $20 \mathrm{cc} / \mathrm{kg} /$ day and total parenteral nutrition was decreased accordingly. He reached his birth weight on the $7^{\text {th }}$ day of admission and as enteral feeding was well-tolerated, on day 10, full enteral feeding was initiated. He was referred to a pediatric cardiologist for a cardiac murmur detected in routine physical examination and diagnosed with PDA. Therefore, oral ibuprofen treatment was started on day 3 . The condition of PDA was outlined by the presence of a minimum of one amongst the subsequent criteria: internal ductal diameter $\geq 1.5 \mathrm{~mm}$, left-atrium-toaortic-root ratio $>1.6$ nonrestrictive, pulsatile transductal flow, reverse or absent diastolic flow within the aorta. On day 
11, physical examination revealed abdominal distention and X-ray investigations showed free air under the diaphragm. The patient was referred to the pediatric surgery department for urgent surgery. The whole abdominal cavity was filled with meconium, and ileum was perforated approximately 15 centimeters away from the proximal ileocecal region. As the perforated area was close to the ileocecal region, ileostomy and colostomy were performed. An area of 30 centimeters was resected. Pathology report confirmed the perforation site. The patient was admitted to NICU and followed closely post-operatively. He was started on vancomycin, meropenem and metronidazole treatments as well as furosemide infusion for acute renal failure. On the $5^{\text {th }}$ day of the operation, ileostomy seemed to be working properly. However, he had recurrent high fever episodes during follow-up, though blood cultures turned out to be negative, and laboratory results showed no pathology except thrombocytopenia and anemia. Treatment was continued. Cranial ultrasonography revealed grade 3 intraventricular hemorrhage. Ophthalmic examination showed grade 1 retinopathy of prematurity. Vancomycin was discontinued on the 10th day. As control acute phase reactants were still elevated (C-reactive protein: $59 \mathrm{mg} / \mathrm{dL}$ ) on the $14^{\text {th }}$ day of the antibiotic regimen, fluconazole was added to the treatment. Twenty days after the surgery, abdominal distention developed and bloody gastric residuals were noted. Oral intake was stopped. The patient received platelet, erythrocyte and fresh frozen plasma infusions to fix the newly detected anemia and thrombocytopenia. Despite all the treatment, he died of multiple organ failure, and his blood cultures confirmed the suspected fungal sepsis. The informed consent form was obtained from the parents of the case.

\section{Discussion}

Gastrointestinal side effects related to ibuprofen are mostly known to occur within the first days of life, late occurrence is rare. In our patient, although full enteral feeding was initiated earlier, abdominal distention developed on the $11^{\text {th }}$ day after birth, without any risk factors or other warning signs of NEC, like nausea or feeding intolerance. Therefore, SIP related to ibuprofen use was the initial diagnosis.

SIP of the newborn is typically found at the terminal ileum (1-5). SIP happens especially in premature infants with very low birth weight (weight $<1500 \mathrm{~g}$ ), and extremely low birth weight (weight $<1000 \mathrm{~g}$ ). SIP is a different clinical entity from NEC, the most severe gastrointestinal complication in premature infants $(1,6,7)$.

In our case, the patient was in the high-risk group as his birth weight was 1210 grams at the $27^{\text {th }}$ gestation week. Our case had no antenatal history of chorioamnionitis.

In a study from the Pediatrix bunch, the organization of antenatal glucocorticoids did not seem to expand the danger of SIP (8). Early organization of postnatal glucocorticoids expands the danger of SIP. However, our case did not receive postnatal or antenatal glucocorticoid treatment (9). In spite of the fact that the postnatal utilization of indomethacin had been already answered to build the danger of SIP, ensuing productions have reported no relationship between indomethacin introduction and $\operatorname{SIP}(9,10)$.

NEC normally develops after the first week of life, after the baby has started to bolster, whereas, in our case abdominal distention was detected on the $11^{\text {th }}$ day after birth, long after the initiation of full enteral feeding. Abdominal radiographic images might reveal pneumoperitoneum, however, in our case there was no sign of pneumatosis intestinalis or portal venous gas, which are the radiograph signs of NEC. Imaging exhibits a gasless stomach area in a few patients with SIP. The average age at aperture placement is seven days with a scope of 0 to 15 days. SIP generally starts earlier than NEC. (mean age; 7 vs. 15 days) (8).

Hazard elements for SIP might fluctuate as per the season of presentation. In a Pediatrix investigation of 633 neonates with SIP, the patients were divided into two based upon their time of presentation (10) as newborn children in the main group $(n=116)$, somewhere around zero and three days of life, who were bigger (middle birth weight $1.4 \mathrm{~kg}$ ) and were less inclined to have gotten antenatal glucocorticoids, indomethacin, surfactant, or mechanical ventilation, and babies in the second group, around 7 and 10 days of life with a mean birth weight of $775 \mathrm{~g}$. In our report, the baby weighed 1210 grams, which is compatible with the second group.

Current treatment of choice for SIP is surgery. Exploratory laparotomy with the resection of the bowel or primary peritoneal drainage (PPD) are the traditional approach. In a previous study, PPD and exploratory laparotomy were compared in the newborns diagnosed with either SIP or NEC, and no difference was found in mortality or prognosis between the two groups (11). In our case, we used exploratory laparotomy with bowel resection in addition to ileostomy and colostomy.

In conclusion, oral ibuprofen treatment for PDA closure may increase the risks for the immature gastrointestinal system. Therefore, intravenous route may be the safer choice for preterm infants.

\section{Ethics}

Informed Consent: Consent form was obtained from the parents of the case.

Peer-review: Externally peer-reviewed.

\section{Authorship Contributions}

Surgical and Medical Practices: Ş.H., S.B., Concept: Ö.B., E.Ö., Design: S..H., E.C., Data Collection or Processing: S.H., Analysis or Interpretation: S..H., E.C., Literature Search: S.B., Writing: S.H.

Conflict of Interest: No conflict of interest was declared by the authors.

Financial Disclosure: The authors declared that this study received no financial support. 


\section{References}

1. Pumberger $W$, Mayr $M$, Kohlhauser $C$, Weninger $M$. Spontaneous localized intestinal perforation in very-lowbirth-weight infants: a distinct clinical entity different from necrotizing enterocolitis. J Am Coll Surg 2002;195:796-803.

2. Attridge JT, Clark R, Walker MW, Gordon PV. New insights into spontaneous intestinal perforation using a national data set: (1) SIP is associated with early indomethacin exposure. J Perinatol 2006;26:93-9.

3. Guthrie SO, Gordon PV, Thomas V, Thorp JA, Peabody J, Clark RH. Necrotizing enterocolitis among neonates in the United States. J Perinatol 2003;23:278-85.

4. Stark AR, Carlo WA, Tyson JE, et al. Adverse effects of early dexamethasone in extremely-low-birth-weight infants. National Institute of Child Health and Human Development Neonatal Research Network. N Engl J Med 2001;344:95101.

5. Uceda JE, Laos CA, Kolni HW, Klein AM. Intestinal perforations in infants with a very low birth weight: a disease of increasing survival? J Pediatr Surg 1995;30:1314-6
6. Alpan G, Eyal F Vinograd I, et al. Localized intestinal perforations after enteral administration of indomethacin in premature infants. J Pediatr 1985;106:277-81.

7. Kawase $\mathrm{Y}$, Ishii T, Arai H, Uga N. Gastrointestinal perforation in very low-birthweight infants. Pediatr Int 2006;48:599-603.

8. Attridge JT, Clark R, Gordon PV. New insights into spontaneous intestinal perforation using a national data set (3): antenatal steroids have no adverse association with spontaneous intestinal perforation. J Perinatol 2006;26:66770.

9. Kelleher J, Salas AA, Bhat R, et al. Prophylactic indomethacin and intestinal perforation in extremely low birth weight infants. Pediatrics 2014;134:1369-77.

10. Attridge JT, Clark R, Walker MW, Gordon PV. New insights into spontaneous intestinal perforation using a national data set: (2) two populations of patients with perforations. J Perinatol 2006;26:185-8.

11. Rao SC, Basani L, Simmer K, Samnakay N, Deshpande G. Peritoneal drainage versus laparotomy as initial surgical treatment for perforated necrotizing enterocolitis or spontaneous intestinal perforation in preterm low birth weight infants. Cochrane Database Syst Rev 2011:CD006182. 